Händehygiene

\section{Weniger waschen, mehr desinfizieren}

— Die Händedesinfektion gilt als wichtigste Maßnahme zur Vermeidung von nosokomialen Infektionen. 86\% des Gesundheitspersonals sind davon überzeugt, dass richtige Händehygiene Infektionen effektiv verhindert. In der Praxis hilft diese Überzeugungen wenig: Im Schnitt wird nicht einmal jede zweite Händedesinfektion, die für den Patientenschutz erforderlich wäre, auch tatsächlich durchgeführt.

Forscher der Universität Ulm sind diesem Phänomen aus sozialpsychologischer Sicht auf den Grund gegangen und fanden heraus: Das Händehygieneverhalten wird maßgeblich durch die implizite Einstellung zur Händehygiene bestimmt. Diese unbewussten Überzeugungen ermöglichen Menschen in Situationen, in denen keine Zeit für kognitives Abwägen möglich ist, handlungsfähig zu bleiben - z.B. bei Stress oder unter Zeitdruck. Verhältnisse, die für den Alltag in der Patientenversorgung typisch sind. Das konkrete Handeln oder Nicht-Handeln erfolgt dann impulsiv auf Basis automatisch aktivierter positiver oder negativer Verknüpfungen im Gedächtnis. Explizit bewusste Einstellungen hatten keinen Einfluss auf die Compliance. Aber: Je positiver die implizite Einstellung von Pflegenden und Ärzten zur Händedesinfektion

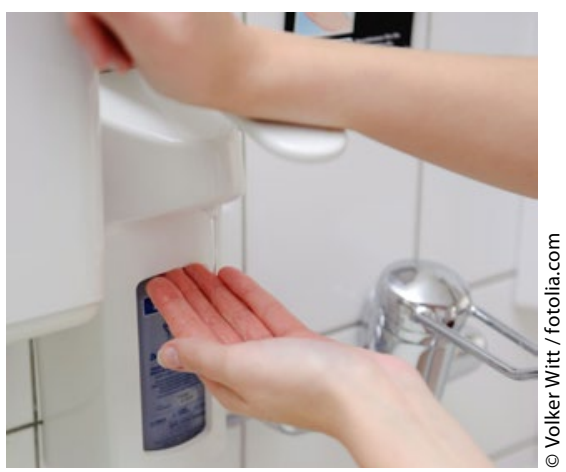

war, desto häufiger desinfizierten sich diese die Hände. Händedesinfektion muss also mit angenehmen Assoziationen verknüpft und als etwas Positives im Gedächtnis archiviert sein. Eine Schlüsselrolle übernimmt dabei das Hautgefühl der Anwender bei der Händedesinfektion. Negativ fällt das Erlebnis aus, wenn der Alkohol des sonst gut verträglichen Hände-Desinfektionsmittels auf eine vorgeschädigte Haut trifft und brennt. Eine Wahrscheinlichkeit, die nicht gering ist, denn 20-30\% der Mitarbeiter im Gesundheitswesen haben Hautirritationen - oft durch zu häufiges Händewaschen.

Eine erfolgversprechende Möglichkeit also, die Compliance zur Händehygiene zu verbessern ist, über ein gutes Hautgefühl bei der Anwendung von Hände-Desinfektionsmitteln die impliziten Einstellungen der Anwender positiv zu beeinflussen.

www.bode-science-center.de
Modellprojekt

Tablets für

Senioren mit Demenz

— Das Modellprojekt „PflegeTab“ will durch moderne digitale Angebote die Lebensqualität von Pflegebedürftigen mit Demenz verbessern. Dabei wendet es sich nicht nur an die Pflegebedürftigen selbst, sondern auch an Pflegekräfte und Angehörige.

Im Rahmen des Projekts soll zunächst eine neuartige Tablet-basierte Anwendung (App) entwickelt werden. Mithilfe der App sollen Pflegekräfte in die Lage versetzt werden, individuell zugeschnittene Aktivierungsangebote für Pflegeheimbewohner mit Demenz zu schaffen. Spielerische und motivierende Elemente passen sich dabei flexibel und automatisch den jeweiligen Ressourcen und Bedürfnissen des Einzelnen

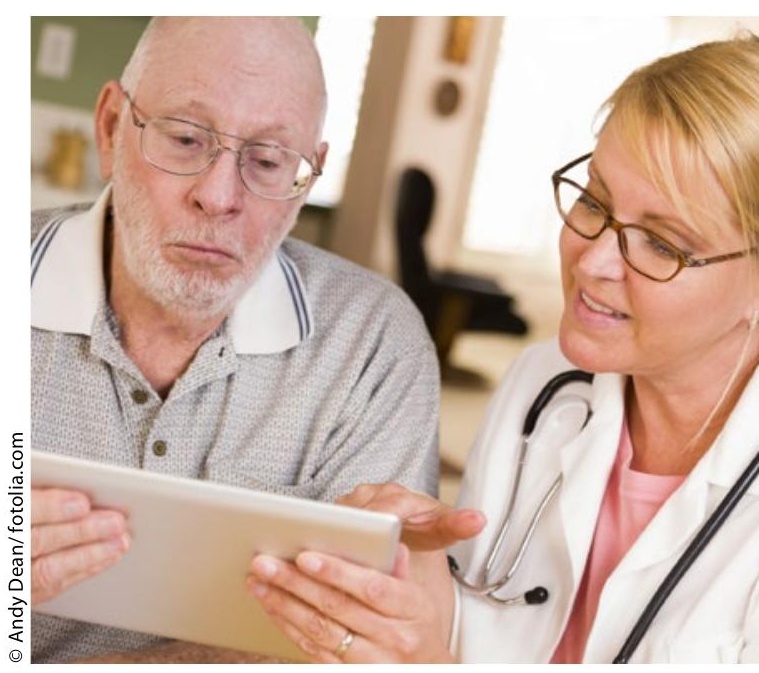

an. Daneben bietet die App eine Reihe leicht zu bedienender Funktionen, die Menschen mit Demenz in ihrer Kommunikation mit Angehörigen oder Pflegekräften unterstützen und fördern können.

Das im Februar 2015 gestartete Verbundprojekt „PflegeTab" wird vom Spitzenverband der Gesetzlichen Krankenversicherungen im Rahmen des Modellprogramms zur Weiterentwicklung der Pflegeversicherung gefördert und hat eine Laufzeit von 36 Monaten. Die Gesamtprojektleitung liegt beim Institut für Medizinische Soziologie und Rehabilitationswissenschaft der Charité Universitätsmedizin Berlin.

www.pflegetab.de 